\title{
Humanización
}

\section{A assistência espiritual e religiosa: contributo para a humanização dos cuidados}

Spiritual and Religious Care: Contribution to the Humanization of Assistance

(2) Autor

\section{Susana Queiroga}

Presidente da Comissão de Ética do ISJD

E-mail: susana.queiroga@isjd.pt 
Resumo

Abstract
O tempo atual é caracterizado pelo individualismo do qual emerge uma constante procura de sentido particularmente quando, por uma situação de doença, o homem é confrontado com a sua finitude. Assim, considerar a espiritualidade enquanto aspeto relevante para o bem-estar dos indivíduos, parece ter razão de ser, em particular se o foco se centrar na humanização dos cuidados.

Our times are characterized by individualism from which arises a constant search for meaning, mostly when a person faces death, caused by disease. Therefore, when we consider the relevance of spirituality to an individual's well-being it somehow has a purpose particularly if we focus on humanization of health care.

Espiritualidade; indivíduo; assistência espiritual; humanização.

Spirituality; individual; spiritual care; humanization.

Recibido: 04/06/2018. Aceptado: 27/08/2018 


\section{Introdução}

A democratização do espaço religioso não requer por si só igualdade, requer fundamentalmente autonomia. 0 princípio de autonomia estimula a diferença e exige que esta diferença não seja, de forma alguma, prejudicada. Trata-se de fomentar a elaboração da individualidade, enriquecendo por isso as relações e as situações.

Uma das formas de constituição lógica do quotidiano é a organização do indivíduo em comunidades e em instituições. Estas obrigam à adesão de um conjunto de regras que, por vezes, se tornam numa espécie de poder, uma forma de mobilização mais do que um fator de limitação. Perante estes aspetos, na preocupação

A implicação dos indivíduos na

determinação das condições

do seu envolvimento pressupõe

que aceitem o carácter racional

e autêntico dos juízos dos

outros

pela consolidação de "relações livres e iguais" estabelece-se, entre os indivíduos, a necessidade de criação das circunstâncias para que as pessoas possam desenvolver as suas potencialidades, evidenciar as suas diversas qualidades, expressar a sua identidade. Uma premissa fundamental é que cada indivíduo respeite os outros, assim como desenvolva a capacidade de aprender a fomentar as suas próprias atitudes. Em consequência, a proteção respeitante ao uso arbitrário da autoridade política e do poder coercivo, pressupõe a negociação das decisões, em certo sentido, por aqueles a quem estas decisões afetam, inclusive se estas forem tomadas por uma minoria mas com consequências para a maioria. A implicação dos indivíduos na determinação das condições do seu envolvimento pressupõe que aceitem o carácter racional e autêntico dos juízos dos outros (Giddens, 1992).

Verifica-se um declínio acentuado das instituições religiosas, nomeadamente nas sociedades ocidentais. Apesar disso, a espiritualidade não se desaloja da reflexividade individual e continua a desempenhar um papel importante na vida de muitas pessoas. Neste sentido, o contexto hospitalar deve contar com um serviço de assistência espiritual e religiosa que responda com efetividade às necessidades deste tipo, detetadas no seio das equipas multidisciplinares de saúde. Para isso será importante que estas equipas assumam a dimensão espiritual como uma dimensão tão importante como as outras, no contexto das práticas hospitalares, incluindo-a como uma forma de humanização de cuidados.

Pretende-se, então, refletir sobre a pertinência de um modelo de cuidados que reflita um entendimento partilhado dos conceitos de espiritualidade, no qual sejam dadas todas as possibilidades de escolha ao doente garantindo, desta forma, uma prestação de cuidados de saúde mais humanizadora.

\section{Sobre o contexto hospitalar}

Não se vive, adoece e morre da mesma maneira quando se pertence a esta ou àquela condição social, aos diferentes géneros, a diversas comunidades étnicas, a diferentes 
culturas e regiões. Mas somos habitualmente deparados com a visão de um mundo da saúde e da doença secularizado, dominado pela consciência de autonomia no que

Os cuidados de saúde

modernos são na sua maioria

dominados pelo modelo

médico, muito científico, ele

mesmo um legado do período

iluminista respeita ao sagrado e pelo desenvolvimento de uma série de saberes e técnicas orientadas para responder aos problemas colocados pela sociedade, tanto na área da saúde como na vida quotidiana.

Uma reflexão muito interessante a este propósito feita por Huang (2011) no seu estudo acerca da caridade médica no movimento budista Tzu Chi situa-se na identificação de uma primeira fase em que as intervenções em saúde se situavam no alívio do sofrimento. Já numa segunda fase, as intervenções em saúde colocavam-se totalmente em torno da ciência e que, atualmente, com a introdução de rituais religiosos prévios à intervenção, esta passava a posicionar-se na esfera do sagrado. Naturalmente, esta identificação tem o seu próprio contexto e está longe do que vivemos atualmente nas unidades de saúde, onde ainda se verifica uma deslocação para fora da área do sagrado no tema da saúde, aspecto particularmente observado de forma radical na medicina (Velasco, 1994).

As enormes possibilidades da medicina atual retiraram-lhe a esfera metafísica e religiosa, mudando-a para a esfera prática (Buytendijk, 1958). Neste sentido, os cuidados de saúde modernos são na sua maioria dominados pelo modelo médico, muito científico, ele mesmo um legado do período iluminista. Sobre este aspeto é pertinente referir o trabalho desenvolvido por Strauss et al. (1985), que reflete a partir das alterações radicais e irrevogáveis que o crescente número de doenças crónicas provocou no trabalho dos médicos, enfermeiros e técnicos de saúde. Foram motivados pelas queixas de que os hospitais vivem um período caracterizado pela hipertecnologia, funcionando muitas vezes como fábricas, de forma desumanizada e com um grau elevado de fragmentação dos cuidados. A medicina excessivamente técnica evoca os tempos em que, apesar de os cuidados de saúde serem menos eficazes, ao doente era oferecida atenção e cuidado, em particular no âmbito da enfermagem, muito vocacionada em minimizar os aspetos mais despersonalizados do hospital. Os profissionais de saúde, no contexto atual, atuam de uma forma tecnicamente orientada, em contraste com o perfil do médico de cabeceira ou da enfermeira cuidadora, que se sabia existir anteriormente. A partir destes pressupostos, a investigação destes autores desenvolveu-se, por observação no contexto hospitalar, com base em três aspetos: em primeiro lugar, os doentes reagem quer ao contexto em que estão, quer ao tratamento que lhes é administrado; em segundo lugar, foi analisada de forma detalhada a relação entre cinco tipos de trabalho (trabalho mecânico, de segurança, de conforto, sentimental e de articulação) e as atividades dos médicos e enfermeiros; e em terceiro lugar, foi dada primazia às tarefas dos profissionais de saúde mais do que à divisão do trabalho propriamente dita.

A utilização do contributo da investigação de Strauss et al. (1985), neste contexto, recai nos tipos de trabalho de conforto e sentimental. Strauss et al. (1985) partem do princípio de que as intervenções médicas podem muitas vezes causar desconforto ao doente. Neste sentido, o trabalho de conforto, muito mais do que uma atitude empática ou a adoção de palavras e gestos adequados, possibilita ao doente o menor desconforto 
possível, aos mais diversos níveis. No hospital, dentro desta perspetiva, o doente estará mais interessado em minimizar o seu desconforto, ao passo que os profissionais de saúde estarão mais orientados para curar a doença propriamente dita. Se o interesse do doente prevalecer, é essencial que se assumam atitudes que atenuem o desconforto experimentado, por exemplo, na espera de um exame, ou nas rotinas de higiene. Por outro lado, o trabalho sentimental focaliza-se na atenção aos detalhes fornecidos pelos doentes e que muitas vezes são ignorados, como por exemplo

No hospital, dentro desta

perspetiva, o doente estará mais interessado em minimizar o seu

desconforto, ao passo que os

profissionais de saúde estarão

mais orientados para curar a

doença propriamente dita a história da pessoa. É mais do que o trabalho de psicologia e, de acordo com Strauss et al. (1985), divide-se em 7 tipos de trabalho: a interação e regras morais, que minimizam o facto de o doente poder ser considerado um objeto; a confiança, na qual os profissionais honram as condições de sigilo e informação ligados à sua atuação; a compostura, relacionada com o toque, o dar a mão; o biográfico, que se prende com a atribuição de importância à história da pessoa; o identitário, que se preocupa essencialmente com o aprofundamento da relação; a realidade e o contexto, no qual a preocupação será a introdução de elementos no discurso que não sejam ilusórios, isto é, não alimentarem no doente situações de ocorrência improvável, que já não encontram cenários de possível concretização; e a retificação, que é a capacidade de apresentar as desculpas ao doente quando se erra. Neste sentido, tomando como base a preocupação pela execução de um trabalho identitário, dentro desta perspetiva do trabalho sentimental de Strauss et al. (1985), poderá ser eficaz tomar em consideração o posicionamento do doente face ao espiritual.

\section{A espiritualidade no modelo holístico dos cuidados}

Considerando os aspetos referidos, entende-se que a proliferação de explicações divinas para os problemas que a medicina não consegue encontrar resposta, associada a uma conceptualização holística dos cuidados de saúde, recoloca a área do sagrado numa dimensão diferente, reunindo a metafísica, a moral e a religião num conceito mais abrangente: o conceito da espiritualidade. As questões existenciais acerca da atribuição de sentido, esperança e propósito estão de novo em voga, na mesma medida em que os indivíduos procuram o bem-estar e a saúde segundo um modelo holístico.

Uma perspetiva que enquadra estes diferentes aspetos é advogada por Kearney (1989). Segundo este autor, relativamente ao conceito de "hospício", e em concreto aos cuidados prestados em doenças terminais, existe um conjunto de procedimentos que devemos considerar, como sejam o controlo dos sintomas, a comunicação efetiva, o suporte à família (incluindo acompanhamento nas situações de sofrimento decorrente da situação de doença), os cuidados espirituais, o suporte profissional, o ensino e a pesquisa. Concretamente, sobre cuidados espirituais Kearney refere que um indivíduo em sofrimento espiritual deve ser uma preocupação dos profissionais de saúde, na mesma medida em que se preocupam também com o sofrimento físico, emocional ou social. Este sofrimento pode encontrar-se muitas vezes de forma independente relativamente 
a uma religião, pelo que o cuidado espiritual não deve ser só uma responsabilidade da figura do capelão; será antes um desafio para todos aqueles que fazem parte de uma equipa multidisciplinar (Kearney, 1989).

Baseado no conceito de total pain ${ }^{1}$ de Saunders e Bains (1983, p. 76), que enquadra a dimensão espiritual ao lado da dimensão física, psicológica e social na conceção deste conceito, Kearney, através de um exemplo prático, centrado na experiência individual de um doente, demonstra o papel da dimensão espiritual (fazendo o mesmo a todos os aspetos que considera na "hospice medicine"): um determinado doente, apesar de não ter uma crença formal, enquadrada numa religião, colocava as seguintes questões -Porquê? Porquê esta dor? Porquê este tempo de espera? Estas questões, ou outras parecidas, assim como a dor propriamente dita, podem ser compreendidas a diferentes níveis. Um desses níveis coloca-as no patamar da "dor espiritual" e, nesta medida, as necessidades espirituais dos doentes devem ser respondidas. Este não é um aspeto para o qual devemos esperar respostas fáceis, em vez disso, cada vez que um membro de uma equipa multidisciplinar acolhe estas questões, encontra-se a ajudar um doente a encontrar algum sentido, reconciliação e mesmo reorganização na situação que está a viver (Kearney, 1989)-.

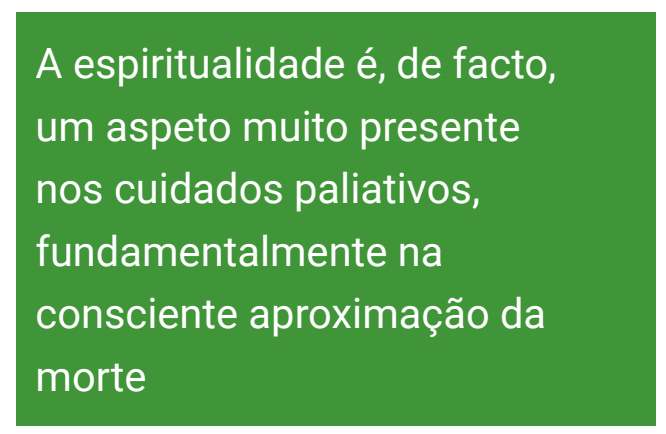

A espiritualidade é, de facto, um aspeto muito presente nos cuidados paliativos ${ }^{2}$, fundamentalmente na consciente aproximação da morte. Barbosa (2003, p. 44) refere que "o ser humano é um ser tríplice: ser corporal, anímico e espiritual. Cada dimensão gera necessidades distintas que devem ser identificadas, valorizadas e tratadas de forma específica". Os cuidados paliativos foram os precursores da abordagem holística nos cuidados de saúde, ao tomarem em consideração os contributos das abordagens alternativas e complementares, ao mesmo tempo que aplicavam os melhores avanços técnico-científicos. Todavia, na prática, tendem a oferecer poucas oportunidades aos próprios profissionais de explorarem a sua espiritualidade em conjunto. Quando uma equipa de saúde tem um entendimento partilhado acerca da espiritualidade consegue envolver todos os membros dessa mesma equipa, ainda que uns se envolvam mais do que outros. Os entendimentos partilhados asseguram que quando se fala em espiritualidade todos conseguem distinguir entre o que é e o que não é do foro espiritual.

As componentes espirituais, religiosas e éticas influenciam a vida do indivíduo ao longo de todas as suas etapas e a forma como cada um desenvolve as suas atividades. A espiritualidade que, segundo O'Brien (1982), é aquilo a que aspira o ser quando deseja

1 Total pain aparece como uma situação, mais do que um sintoma, comparada a um icebergue cuja ponta é a dor e submersos estão os aspetos físicos, psicológicos sociais e espirituais.

2 Segundo Barbosa (2003, p. 47) "os cuidados paliativos, porfiando a abordagem integral do doente (aspetos físicos, emocionais, sociais e espirituais), incorporando a família no seu estudo e estratégia, promovendo o princípio de autonomia e dignidade da pessoa doente e remetendo para um cuidado personalizado e continuado, poderão instaurar-se como um recomeço de uma renovada forma de entender e praticar a medicina». Os cuidados paliativos «dão resposta às necessidades físicas, psicológicas, sociais e espirituais e, se necessário, prolongam-se no acompanhamento do luto da família. Destinam-se ao doente (não doença) e sua família e o objetivo é proporcionarem apoio e cuidados aos doentes nas últimas fases de sua doença". 
transcender o domínio da matéria, é muitas vezes negligenciada. As características da espiritualidade combinadas com as emoções e os aspetos físicos representam situações de totalidade. Por outro lado, as orientações religiosas, as crenças e o significado da vida refletem-se em padrões éticos e por conseguinte nas ações e nas práticas. A espiritualidade, conceito de facto mais abrangente que religião, envolve abordagens teístas e não teístas que podem ser aplicadas a agnósticos e ateus, assim como a seguidores de religiões reconhecidas, já que, por exemplo, face à morte, "o projeto antropológico, reduzido a instantes que se devoram na

As características da

espiritualidade combinadas

com as emoções e os aspetos

físicos representam situações

de totalidade desidentificação/desontologização e na decorrente solidão e desamparo, pode atingir um paroxismo intolerável de desumanização e alienação, apesar de novas e miscigenadas formas de reinvestimento no sagrado, numa elaborada economia do simbólico e do virtual"'3. Reconhece-se assim, a presença da dimensão espiritual em todos os indivíduos, independentemente da fase em que se encontra ou da forma como ela se revela.

Considerando então a dimensão espiritual como um fator primordial para a prestação de cuidados entendidos como holísticos, como é que deve ser considerada a sua aplicação? Barbosa $(2003$, p. 45) oferece uma pista:

Para escutar o sofrimento espiritual, o profissional deverá começar por escutar o seu, para que se permita que alguém seja plenamente si mesmo, indo mais além, e favorecer uma tal abertura, desejo de consumação: pela presença, escuta em todo o seu invisível -o seu sofrimento (compaixão)- deixar-se contaminar pelo sofrimento do outro, acolhendo-o sem ficar afogado no sofrimento do outro, o seu desejo, o ser que nele deseja (pois é parte do desconhecido de nós mesmos que a morte pode revelar), atitude de confiança na profundidade do homem, naquilo que no homem se mantém aberto a um além do homem.

Reencontramos então um renascimento da "medicina holística" onde o objetivo da saúde assenta muito para além das "medições" e "tecnicidades" que abrangem uma rede de relações habitualmente complexas. Para além do transcendente, em primeiro lugar temos o indivíduo e a sua relação consigo mesmo, o ter um propósito ou um sentido para a vida, um quadro moral que leva a posicionamentos mais positivos e negativos relativamente ao mundo. Em segundo lugar, o indivíduo tem uma relação com o mundo natural que o rodeia. Em terceiro, mantém relações interpessoais e relações terapêuticas que lhe transmitem confiança e promovem um tratamento efetivo. $\mathrm{Na}$ abordagem holística aparece referida esta complexa rede de relações ligadas à componente espiritual dos cuidados. Várias questões podem ser colocadas, nomeadamente as que se prendem com o processo de desenvolvimento do entendimento partilhado, em contexto multidisciplinar de cuidados, por exemplo, deste complexo espiritual. Uma delas 
situa-se no como integrar este aspeto nas práticas, outra poderá ser o como agir de modo mais confiante neste aspeto tão particular da condição humana.

A abordagem holística é parte de uma imagem difusa e uma mistura incerta de misticismo, modos de vida e estilos de vida, que inclui no seu quadro alargado, tanto as medicinas complementares, como qualquer aconselhamento à la carte de um qualquer agente, disponível num qualquer suporte de comunicação e informação (jornal diário, televisão, internet, etc.). Isto deixa livre toda uma área de difícil acesso, quer na compreensão partilhada do que é a espiritualidade, quer no desenvolvimento de um grau de discernimento acerca desta realidade compósita, resultando, em ultima análise, o descurar desta dimensão.

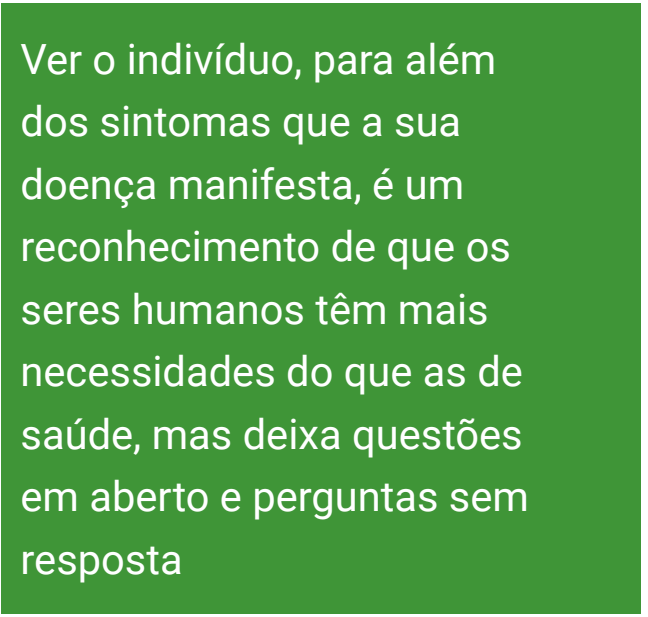

Não sendo propriamente uma novidade, a abordagem holística necessita de alguma reflexão ao nível dos cuidados de saúde, nomeadamente no modo de entender e colocar em prática os seus conceitos. Como ingredientes nesta reflexão aparecem quatro que são fundamentais: o corpo, a mente, os elementos sociais e a espiritualidade. Estes elementos que se ligam de forma imbricada produzem um ser único e individual. Se negligenciarmos qualquer um destes ingredientes poderemos ter esta abordagem bastante comprometida.

As limitações dos modelos médicos, com raízes profundas na filosofia cartesiana, e dos modelos sociais, deles largamente tributários, baseados na prevenção das doenças através da criação de melhores condições ambientais e sociais, revelam-se de um modo muito particular nos crescentes problemas que emergem da gestão dos casos de internamentos de longa duração. A este aspeto junta-se a iniciativa de cada indivíduo, principalmente quando procura alternativas fora dos contextos mais ortodoxos. Perante toda a oferta existente, e alguma desta oferta aparentemente produz certos contributos que se manifestam de modo positivo, é necessário que as equipas de saúde pensem de um modo mais profundo no modelo de saúde que protagonizam e no tipo de cuidados de saúde que prestam, reconhecendo a totalidade do indivíduo, e a importância que certos elementos têm, nomeadamente na criação de condições para um maior bem-estar ${ }^{4}$. A perceção de que os seres humanos são complexos na sua totalidade e que se inserem num ambiente também ele complexo, assume particular importância num contexto moderno e pós-moderno, pois muitas vezes este contexto parece ser fragmentado, deslaçado e com um sentido de anomia face ao bem-estar.

A perspetiva holística dos cuidados de saúde é uma visão cuja discussão permanece ativa e atual, uma vez que, apesar de defendida por muitos profissionais e escolas de saúde, dificilmente a encontramos na prática clínica. Ver o indivíduo, para além dos sintomas que a sua doença manifesta, é um reconhecimento de que os seres huma-

4 Damos como exemplos a aromaterapia, a musicoterapia ou as salas de snoezelen (salas que proporcionam estimulação cognitiva, conforto e relaxamento utilizando vários estímulos sensoriais). 
nos têm mais necessidades do que as de saúde, mas deixa questões em aberto e perguntas sem resposta. Uma delas poderá ser, por exemplo, saber até que ponto outras necessidades são efetivamente importantes, de modo a que, ao serem envolvidas, possam afetar objetivamente os resultados de um determinado tratamento. A importância da dimensão espiritual no contexto da saúde pode inclu-

Uma abordagem multidisciplinar dos cuidados, que aceite

a realidade espiritual e 0

significado do espírito humano, pode ajudar a corrigir as formas fragmentadas dos cuidados,

baseadas em "especialidades",

que são ainda norma nas práticas hospitalares sive equacionar-se na medida em que a experiência da doença é interiorizada enquanto fenómeno de experiência individual, tal como também é interiorizada a espiritualidade. Dois aspetos a ter em conta: o primeiro é o facto de cada indivíduo necessitar de diferentes elementos para se sentir bem; o segundo é o facto de estes elementos estarem intimamente integrados e interligados, em vez da sua existência em separado.

A abordagem holística procura reconhecer e promover um estado de harmonia quando trata cada indivíduo como um todo. 0 tradicional modelo biomédico, ao enfatizar o elemento físico da doença, de certo modo negligencia, ou nega até, outros elementos, e falha no entendimento da experiência humana da doença na sua totalidade. Uma abordagem multidisciplinar dos cuidados, que aceite a realidade espiritual e o significado do espírito humano, pode ajudar a corrigir as formas fragmentadas dos cuidados, baseadas em "especialidades", que são ainda norma nas práticas hospitalares. Se tomamos o indivíduo como um todo, o cuidado espiritual, desmembrado de tudo o resto é insuficiente para o seu restabelecimento. Isto só é possível se esta abordagem multidisciplinar mantiver o diálogo entre as diferentes disciplinas para o desenvolvimento de formas adequadas de olhar o indivíduo como um todo, incluindo o lado mais misterioso e menos tangível que emerge do espírito humano e da forma como conduz a sua espiritualidade individual.

No que respeita a uma abordagem holística, entre aquilo que é transmitido aos futuros médicos e enfermeiros, durante a sua preparação para a vida profissional, e o que se desenvolve na prática, transforma-se numa fragmentação dos cuidados, ou seja, apesar de se considerar a espiritualidade como uma das componentes básicas do modelo, na prática é omissa, uma vez que as preocupações dos cuidados se focam fundamentalmente no corpo e na mente (Oldnall, 1996). Algumas razões para este facto são, por exemplo, uma visão limitada do conceito de espiritualidade, remetendo os cuidados para "profissionais de religião" (Carson, 1989); medo de não ter competência para as solicitações apresentadas (Granstrom, 1995); incerteza no que respeita às suas próprias crenças e valores religiosos e espirituais (Harrington, 1995); falta de tempo ou rácios insuficientes de pessoal (Boutell \& Bozett, 1987; Highfield, 1992; Piles, 1990; Sodestrom \& Martinson, 1987); medo de impor as suas próprias crenças ao doente (Pullen, Tuck, \& Mix, 1996); medo de intromissão na privacidade do doente (Harrington, 1995); e problemas na real avaliação das necessidades espirituais, consideradas muitas vezes como apenas fazendo parte das preocupações da área da psicologia; insuficiente preparação para esta dimensão ao nível da formação dos profissionais, sendo que por vezes até é inexistente (Oldnall, 1996). 


\section{Espiritualidade como desafio humanizador}

A dimensão religiosa e espiritual está entre os fatores mais importantes na estruturação de toda a experiência do indivíduo, na constituição do seu sistema de crenças, valores, comportamentos e, consequentemente, nos seus padrões de doença. Os indivíduos vivem num constante processo de exploração, contemplação (ontológica) ${ }^{5}$, nos mais variados sectores da sua vida quotidiana, nos quais também circulam o seu sentido particular de esperança, do amor ou do transcendente. Uma abordagem que considera a espiritualidade fornece explicações que poderão ajudar a procura da cura ou, pelo menos, o controlo dos sintomas de

Estaremos perante a introdução de uma nova forma de poder sobre a vida, isto é, para além do "corpo como máquina" e do "corpo como organismo" uma determinada situação de doença, a partir das atribuições de sentido que o indivíduo faz da sua existência e da sua realidade.

Assim, aos profissionais de saúde é-lhes ainda pedido um sentido de responsabilidade ética quando olham para o indivíduo na sua totalidade e reconhecem a espiritualidade de cada um, com o objetivo de a respeitarem e a entenderem em cada indivíduo como sendo único. Neste contexto é necessário o entendimento de que os indivíduos têm experiências holísticas, de que as doenças as afetam nessa medida e de que os cuidados têm de se tornar mais profundos, mais totais, mais transcendentes do que uma abordagem médica ou social.

$\mathrm{Na}$ prática, os desafios que se colocam a esta perspetiva podem ser elencados da seguinte forma: por um lado, aos doentes é-lhes dada uma escolha, baseada na informação e na acessibilidade, por outro lado, o trabalho passa a ser de equipa multidisciplinar, sem a predominância de umas disciplinas face a outras.

o primeiro desafio elencado é ele mesmo visto como um valor de alta qualidade dos serviços, uma vez que se baseia na atribuição do papel principal ao doente. Por exemplo, a Joint Commission on Accreditation of Healthcare Organizations enquadra, como aspecto da sua política, o facto de que, para muitos doentes, a pastoral e outros serviços espirituais, serem uma parte integrante dos cuidados de saúde e do quotidiano em geral, pelo que os hospitais devem estar habilitados a fornecer este tipo de cuidados aos doentes que o solicitem.

Na mudança desta abordagem podemos esta perante uma mudança de poder: dos profissionais de saúde, do saber-poder dominante do médico e do saber-poder periférico dos enfermeiros (Carapinheiro, 2005) para o saber (poder) profano dos doentes. Estes últimos podem tornar-se cada vez mais envolvidos na decisão dos cuidados que Ihes são ministrados e mais críticos face aos serviços, uma vez que exigem a referida qualidade. Estaremos perante a introdução de uma nova forma de poder sobre a vida, isto é, para além do "corpo como máquina" e do "corpo como organismo" (Carapinheiro,

5 A contemplação, indicada aqui como ontológica, é uma tradução livre para a expressão inglesa wonder, no sentido de se constituir um ato que supera a divisão tradicional entre a experiência subjetiva e a experiência objetiva, incluindo a participação na essência e na natureza da base divina de uma determinada pessoa ou objeto. Leva o indivíduo, para além da sua individualidade, a participar no todo ontologicamente maior. 
2005), deparamo-nos com o corpo auto-controlado ou o corpo como meio de decisão? A exigência decorre ao nível dos cuidados, por um ambiente confortável, seguro, calmo; decorre ao nível da informação, uma vez que ao adquiri-la, faz melhores escolhas, tem confiança e sentimento de controlo na situação; decorre ao nível da comunicação, pois podem expressar-se e serem ouvidos como iguais; ao nível da relação, porque são tratados com igualdade, respeito e dignidade. Será talvez a superação da "inviabilidade institucional, a inoportunidade funcional e a ilegitimidade estrutural das possibilidades estratégicas dos doentes" que até agora poderia estar a repousar "na determinação da natureza das suas culturas leigas, como destituídas de expressão, desapossadas de ação, expurgadas de sentido social e objetificadas em corpos inertes e passivos" (Carapinheiro, 2005, p. 395).

Estes aspetos realçam também a importância que as crenças e os valores dos indivíduos passam a ter para os sistemas de saúde, representando esta oportunidade um dos maiores desafios, tanto para os doentes, como, fundamentalmente para os profissionais. Apresenta-se a necessidade de articular as crenças e valores de cada profissional de saúde com a de cada doente, bem como de entender qual o uso e significado a dar aos resultados desta aproximação, digamos assim.

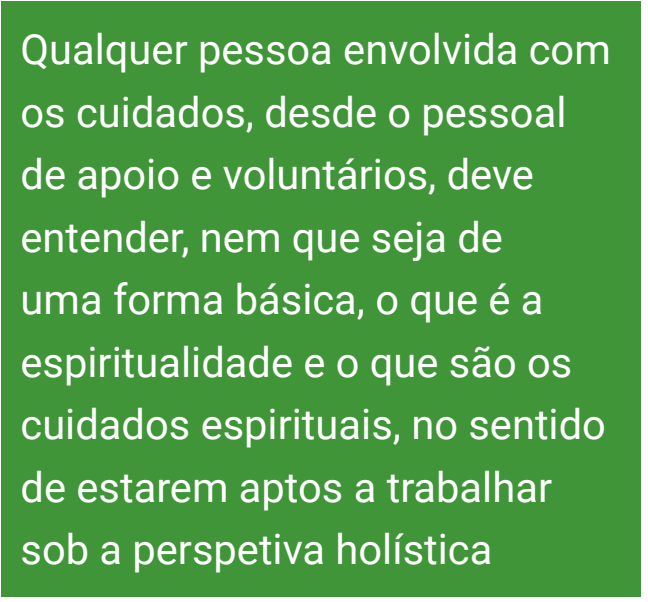

As tradicionais estruturas de poder percorreram um caminho evolutivo assente em dois eixos, o da medicina científica e o da medicina social (Carapinheiro, 2005) e que mais recentemente deram origem a um conjunto de reflexões sobre o hospital e os cuidados que assentam na análise do poder médico (Carapinheiro, 1993). Estas estruturas são agora desafiadas, no que diz respeito ao trabalho de equipa multidisciplinar, pelo reconhecimento de muitas perspetivas diferentes nos cuidados aos doentes, perante uma especialização crescente, associada a uma limitação constante dos recursos e a par de uma mudança tecnológica contínua e rápida.

Neste sentido, qualquer pessoa envolvida com os cuidados, desde o pessoal de apoio e voluntários (que habitualmente não são considerados na equação dos cuidados), deve entender, nem que seja de uma forma básica, o que é a espiritualidade e o que são os cuidados espirituais, no sentido de estarem aptos a trabalhar sob a perspetiva holística. Talvez um bom entendimento da espiritualidade humana seja a chave para o restabelecimento dos serviços de saúde de filosofia holística, eficientes e com elevados padrões de excelência. A inclusão da espiritualidade na agenda das equipas prestadoras de cuidados pode ajudar a alcançar esta realidade.

0 estudo do impacto da espiritualidade tem encontrado um grande vigor, particularmente nos temas relacionados com a morte, o coping e a recuperação. Relativamente aos primeiros, existem estudos que referem, por exemplo, que os indivíduos que têm prática religiosa ou espiritual regular têm tendência a viver mais tempo (Strawbridge, 1997). No que diz respeito ao coping, existem estudos que referem que os doentes que estão mais preparados no que diz respeito à sua dimensão espiritual; utilizam o 
seu sistema de crenças para poderem lidar com a sua doença, com a dor que essa doença possa provocar ou o stress associado à adaptação à nova situação. Alguns estudos referem ainda que quem tem uma melhor preparação espiritual, apresenta uma perspetiva mais positiva face aos aspetos da vida em geral e à

Quanto aos estudos sobre a
recuperação, há uma tendência
para a recuperação de doenças
ou de intervenções cirúrgicas
nos indivíduos com prática
religiosa ou espiritual regular
doença em particular, apresentam uma vida com mais qualidade e, inclusive, lidam melhor com a morte (Yates, 1981; Cohen, 1995). Quanto aos estudos sobre a recuperação, há uma tendência para a recuperação de doenças ou de intervenções cirúrgicas nos indivíduos com prática religiosa ou espiritual regular (Harris, 1995).

0 valor que reside numa prestação de cuidados que admite uma intervenção em todas as dimensões da vida de um indivíduo pode, na prática, permitir que se responda de forma mais efetiva, segundo Puchalski (2001):

- Ao considerarmos a espiritualidade, podemos introduzir um dinamismo no entendimento da doença, na medida em que, ao valorizar a maneira como o indivíduo se relaciona com Deus, de acordo com as suas convicções religiosas, o indivíduo poderá aceitar (que não será sinónimo de resignação), ou não, as circunstâncias provocadas pela sua doença.

- Por outro lado, as convicções religiosas ou a forma como o doente entende a sua espiritualidade chocam por vezes com os procedimentos que têm de se encetar para melhorar a condição de um determinado doente. Assim, as convicções religiosas afetam, por vezes, a saúde do indivíduo ou, noutras alturas, condicionam as decisões que têm de ser tomadas face a uma situação de doença.

- A espiritualidade pode ser uma necessidade do doente, e pode ser um fator muito importante no modo como ele lida com a doença.

Na perspectiva de Puchalski (2001), considerando a espiritualidade do indivíduo doente como um aspeto muito importante nos cuidados de saúde, os profissionais de saúde que pretendem considerar esta dimensão deverão atuar no sentido de serem uma presença total, preferencialmente compassiva (no sentido empático do termo, ou seja, sofrer com) conforme nos refere também Barbosa (2003), ouvindo os medos, esperanças, dor e expectativas dos doentes, obter a sua "história" espiritual, estar atentos a todas as dimensões, não só do doente mas também da sua família, incorporar o conceito de "práticas espirituais" como algo apropriado e envolver os capelães, ou outros profissionais preparados para responder a esta dimensão, como membros da sua equipa interdisciplinar de cuidados. Sobre estes aspetos, Puchalski refere ainda que, apesar de considerar que os profissionais de saúde podem, de um modo geral, ser garantes de uma primeira intervenção, nomeadamente na recolha de informação primária para proceder a um encaminhamento adequado, aquilo que chama de entrevistas em profundidade, devem ser conduzidas por capelães habilitados, ou como referimos, profissionais preparados, uma vez que estarão mais capacitados para agir eficazmente. 


\section{Considerações finais: a assistência espiritual no quotidiano hospitalar}

O foco de análise do fenómeno religioso tende a deslocar-se da religião, por referência a um Deus, para a espiritualidade, mais dedicada ao propósito e ao sentido da vida. É a identificação de uma viragem subjetiva do foco de análise. Para esta viragem poderá ter contribuído a já referida perda da influência religiosa institucional, nos indivíduos e na sociedade, e o que se pode chamar de privatização do fenómeno religioso. As mudanças provocadas por esta privatização do fenómeno religioso e pela redução da influência da religião instituída aumentaram o interesse no conceito de espiritualidade. $A$ espiritualidade per se não pode ser, no entanto, reduzida ao âmbito desta privatização, uma vez que também se reflete nos comportamentos e posicionamentos sociais dos indivíduos: as escolhas individuais, apesar de aparentemente parecerem únicas e personalizadas, são sistematicamente influenciadas pelo conjunto, pela sociedade em que estão inseridas, pelo entretecimento que a vida em sociedade provoca.

O desafio que se coloca

aos profissionais de saúde

é o de ajudar os doentes a

encontrarem sentido na sua

situação de doença

0 conceito de espiritualidade, ainda que esteja localizado em variados contextos, ele é associado a aspetos ligados a uma religiosidade experimental, interior, ligada de uma forma geral às dimensões subjetivas da identidade de cada indivíduo. Este conceito tem por isso a necessidade de ser adaptado conforme o contexto em que ele é analisado, levando a que os profissionais de saúde, quando o consideram nas suas práticas quotidianas ou no seio do seu modelo de cuidados, o devam fazer na exata medida em que o doente também o considera. Para melhor entender o nível de importância desta dimensão é importante ter em conta as experiências individuais. Constrói-se então a espiritualidade como um processo em desenvolvimento, como um sistema de crenças e valores, revelador da necessidade que cada um tem em entender o sentido da sua vida, da transcendência ou de procurarem algum preenchimento a nível espiritual. Estamos perante uma grande variedade e diversidade de escolhas.

O desafio que se coloca aos profissionais de saúde é o de ajudar os doentes a encontrarem sentido na sua situação de doença (Puchalski, 2001). É importante não esquecer também que a religião e a espiritualidade podem muito bem surgir da experiência corporal: a experiência corporal pode evocar a necessidade de satisfazer a dimensão espiritual na medida em que a doença evoca também ela, a sensação de limite ou finitude. 0 facto de o indivíduo se encontrar mais fraco no corpo e nas suas emoções faz emergir uma nova identidade (Glucklich, 2001). O corpo é veículo da identidade (Giddens, 1992), num hospital cujo ambiente pode ser considerado hostil (Strauss et al., 1985) colocando o indivíduo em situação de desabrigo do seu contexto, fora do seu território habitual. E assim sendo, poderá tender a procurar o seu junto dos que Ihe podem transmitir segurança e construção de significados, facilitando elementos interpretativos da realidade.

O hospital torna-se o palco privilegiado para a constatação de que os indivíduos não acreditam todos nas mesmas coisas ou atuam previsivelmente de uma mesma forma 
(Augsberger, 1986). De facto, na atualidade, temos de ser impelidos a avaliar o sistema de crenças de forma plural, em que cada indivíduo procede às suas escolhas, quase de forma sistemática e ficamos à mercê das consequências que o elevado grau de reflexividade provoca na vida humana. 0 indivíduo constrói os seus próprios contextos e, quando procura Deus, fá-lo por si mesmo, delineando as suas próprias trajetórias. As transformações provocadas pela situação de doença (Glucklich, 2001) desafiam os indivíduos a colocar novas prioridades na sua existência. Na prática, o indivíduo procura no hospital uma resposta para a sua doença ou mal-estar. Procurará antes de tudo resolver o seu problema de saúde e o desconforto que ele acarreta (Strauss et al., 1985).

Nesta perspetiva, a inclusão da abordagem terapêutica da dimensão espiritual no processo geral dos cuidados é contributo efetivo para a concretização de cuidados mais humanizadores. O homem é visto no seu todo, com toda a sua circunstância. Esta inclusão, embora continue a avançar timidamente, carece ainda de uma nivelação discursiva e dentro do contexto da equipa, da constituição de um corpo de saberes próprio e potencialmente evolutivo que não fique refém dos contextos institucionais tradicionais. Espera-se mais, portanto estimule-se a sua reflexão e discussão.

\section{Bibliografia}

Augsberger, D. W. (1986). Pastoral Counselling Across Cultures. Philadelphia: Westminster Press.

Barbosa, A. (2003). Pensar a morte nos cuidados de saúde. Análise Social, XXXVIII(166), 35-49.

Boutell, K. A., \& Bozett, F. W. (1987). Nurses' Assessment of Patients' Spirituality: Continuing Education Implications. Journal of Continuing Education in Nursing, (21), 172-176.

Buytendijk, F. J. J. (1958). A dor. Revista Occidente.

Carapinheiro, G. (1993). Saberes e Poderes no Hospital. Uma sociologia dos Serviços Hospitalares. Porto: Edições Afrontamento.

Carapinheiro, G. (2005). Do bio-poder ao poder médico. Estudos do Século XX, (5), 383-398.

Carson, V. B. (1989). Spiritual Dimensions of Nursing Practice. Philadelphia: Saunders.

Cohen, R., Mount, B., Strobel, M. G., \& Bui, F. (1995). The McGill Quality of Life Questionnaire: a measure of quality of life appropriate for people with advanced disease. A preliminary study of validity and acceptability. Palliative Medicine, (9), 207-219. DOI: https://doi.org/10.1177/026921639500900306

Giddens, A. [1998 (1992)]. La transformación de la intimidad. Sexualidad, amor y erotismo en las sociedades modernas (2. ${ }^{\text {a }}$ ed.). Madrid: Ediciones Cátedra - Teorema.

Glucklich, A. (2001). Sacred Pain: Hurting the Body for the Sake of the Soul. Oxford: Oxford University Press.

Granstrom, S. (1995). Spiritual Care for Oncology Patients. Topics in Clinical Nursing, 1(7), 39-45.

Harrington, A. (1995). Spiritual Care: What Does it Mean to Registered Nurses? Australian Journal of Advanced Nursing, 4(12), 5-14.

Harris, R. C., Dew, M. A., Lee, A., Amaya, M., Buches, L., Reetz, D. \& Coleman, G., (1995). The role of religion in heart-transplant recipients' long-term health and well-being. Journal of Religion and Health, 34(1), 17-32. DOI: https://doi.org/10.1007/BF02248635 
Highfield, M. F. (1992). Spiritual Health of Oncology Patients: Nurse and Patient Perspectives. Cancer Nursing, (15), 1-8. DOI: https://doi.org/10.1097/00002820-199202000-00001

Huang, C. J. (2011). Scientific and Sacramental: Medical Charity in the Buddhist Tzu Chi Movement. Presentation at $31^{\text {st }}$ International Society for the Sociology of Religion Conference, (entre 30 de Junho e 3 de Julho de 2011) Aux-en-Provence.

Kearney, M. (1989). Hospice Medicine. In Changing Ideas in Health Care. Oxford: John Wiley \& Sons, Lda.

O'Brien, M. (1982). The need for spiritual integrity. In H. Yura \& M. Walsh (Eds), Human needs and nursing process (pp. 85-95). Norwalk, Connecticut, Appleton-Century-Crofts.

Oldnall, A. (1996). A Critical Analysis of Nursing: Meeting the Spiritual Needs of Patients. Journal of Advanced Nursing, (23), 138-144. DOI: https://doi.org/10.1111/j.1365-2648.1996.tb03145.x

Piles, C. L. (1990). Providing Spiritual Care. Nurse Education, (15), 36-41. DOI: https://doi.org/10.1097/00006223199001000-00014

Puchalski, C. M. (2001). The role of spirituality in health care. Apresentação feita na Baylor University Medical Center em 28 de Fevereiro de 2001. DOI: https://doi.org/10.1080/08998280.2001.11927788

Pullen, L., Tuck, I., \& Mix, K. (1996). Mental Health Nurses - Spiritual Perspectives. Journal of Holistic Nursing, 2(14), 85-97. DOI: https://doi.org/10.1177/089801019601400202

Saunders, C, \& Baines, M. (1983). Living with Dying: The management of terminal disease (2. ed.). Oxford: Oxford University Press.

Strauss, A. L., Fagerhaugh, S. Y., Suczek, B., \& Wiener, C. (1985). Social Organization of Medical Work. Chicago: The University of Chicago Press.

Strawbridge, W. J., Cohen, R. D., Shema, S. J., \& Kaplan, G. A. (1997). Frequent attendance at religious services and mortality over 28 years. American Journal of Public Health, (87), 957-961. DOI: https://doi. org/10.2105/AJPH.87.6.957

Velasco, J. M. (1994). Mundo de la salud y evangelización. Madrid: Congreso Iglesia y salud.

Yates, J. W., Chalmer, B. J., St. James, P., Follansbee, M., \& Mckegney, F. P. (1981). Religion in patients with advanced cancer. Medical and Pediatric Oncology, 9(2), 121-128. DOI: https://doi.org/10.1002/ mpo.2950090204 